\title{
Midbrain Dopamine Receptor Availability Is Inversely Associated with Novelty-Seeking Traits in Humans
}

\author{
David H. Zald, ${ }^{1,2}$ Ronald L. Cowan, ${ }^{2,3}$ Patrizia Riccardi, ${ }^{4}$ Ronald M. Baldwin, ${ }^{3}$ M. Sib Ansari, ${ }^{3}$ Rui Li, ${ }^{3}$ Evan S. Shelby, ${ }^{1}$ \\ Clarence E. Smith, ${ }^{3}$ Maureen McHugo, ${ }^{1}$ and Robert M. Kessler ${ }^{3}$ \\ Departments of ${ }^{1}$ Psychology, ${ }^{2}$ Psychiatry, and ${ }^{3}$ Radiological Sciences, Vanderbilt University Nashville, Tennessee 37240, and ${ }^{4}$ Department of Nuclear \\ Medicine, Albert Einstein College of Medicine, Bronx, New York 10461
}

\begin{abstract}
Novelty-seeking personality traits are a major risk factor for the development of drug abuse and other unsafe behaviors. Rodent models of temperament indicate that high novelty responding is associated with decreased inhibitory autoreceptor control of midbrain dopamine neurons. It has been speculated that individual differences in dopamine functioning also underlie the personality trait of novelty seeking in humans. However, differences in the dopamine system of rodents and humans, as well as the methods for assessing novelty responding/seeking across species leave unclear to what extent the animal models inform our understanding of human personality. In the present study we examined the correlation between novelty-seeking traits in humans and $D_{2}$-like $\left(D_{2} / D_{3}\right)$ receptor availability in the substantia nigra/ventral tegmental area. Based on the rodent literature we predicted that novelty seeking would be characterized by lowered levels of $\mathrm{D}_{2}$-like (auto)receptor availability in the midbrain. Thirty-four healthy adults (18 men, 16 women) completed the Tridimensional Personality Questionnaire-Novelty-Seeking Scale and PET scanning with the $\mathrm{D}_{2} / \mathrm{D}_{3}$ ligand $\left[{ }^{18} \mathrm{~F}\right]$ fallypride. NoveltySeeking personality traits were inversely associated with $\mathrm{D}_{2}$-like receptor availability in the ventral midbrain, an effect that remained significant after controlling for age. We speculate that the lower midbrain (auto)receptor availability seen in high novelty seekers leads to accentuated dopaminergic responses to novelty and other conditions that induce dopamine release.
\end{abstract}

Key words: autoreceptor; dopamine; $\mathrm{D}_{2}$; ventral tegmental area, substantia nigra; emotion; motivation; reward; personality

\section{Introduction}

The personality trait of novelty seeking taps the extent to which a person responds to novel stimuli or situations with exploratory activity and positive excitement (Cloninger, 1986). The trait is among the best predictors of drug use and other risky behaviors (Howard et al., 1997). Rodent studies provide a parallel to human novelty seeking, in that rodents who show higher motor responses to novel environments are more vulnerable to developing self administration of psychostimulants (Piazza et al., 1989). Neuropharmacological studies indicate that high novelty responsive rodents possess higher basal and stimulated extracellular dopamine (DA) levels in the nucleus accumbens compared with low novelty responders (Bradberry et al., 1991; Piazza et al., 1991a; Hooks et al., 1992). This heightened DA release appears to be at least partially a consequence of weakened autoreceptor control of midbrain DA producing neurons, in that high novelty responding rodents show reduced $\mathrm{D}_{2}$ receptor-induced (presumably autoreceptor mediated) inhibition of DA firing (Marinelli and White, 2000).

Within the DA midbrain, somatodendritic $\mathrm{D}_{2}$-like autoreceptors provide inhibitory regulation of DA neuron firing (Aghaja-

\footnotetext{
Received May 28, 2008; revised 0ct. 14, 2008; accepted Nov. 5, 2008.

This work was supported by National Institutes of Health Grant 1R01 DA019670-02.

Correspondence should be addressed to Dr. David H. Zald, Department of Psychology, PMB 407817, 2301 Vanderbilt Place, Nashville, TN 37240. E-mail: david.zald@vanderbilt.edu.

DOI:10.1523/JNEUROSCI.2423-08.2008

Copyright $\odot 2008$ Society for Neuroscience $\quad$ 0270-6474/08/2814372-07\$15.00/0
}

nian and Bunney, 1977; White and Wang, 1984; Lacey et al., 1987; Mercuri et al., 1992). Somatodendritic autoreceptors influence both the local somatodendritic release of DA as well as DA release from axon terminal regions, with the relative strength of these effects varying depending on the DA cell group and terminal region (Maidment and Marsden, 1985; Westerink et al., 1996; Cragg and Greenfield, 1997; Chen and Pan, 2000; Adell and Artigas, 2004). $\mathrm{D}_{2}$-short receptors are the most abundant autoreceptor subtype in the midbrain (Sesack et al., 1994; Khan et al., 1998), and provide potent inhibition of DA release (Mercuri et al., 1997). Somatodendritic $\mathrm{D}_{3}$ receptors (Diaz et al., 2000) have also been observed to play an autoreceptor function (Levant, 1997; Tepper et al., 1997), but are less abundant (Tepper et al., 1997; Gurevich and Joyce, 1999) and provide a more limited regulatory influence than $\mathrm{D}_{2}$ autoreceptors (Millan et al., 2000; Sokoloff et al., 2006). A smaller fraction of $\mathrm{D}_{2}$-like receptors also localize to glutamatergic inputs to DA neurons (Pickel et al., 2002), providing an additional route through which midbrain $\mathrm{D}_{2}$-like receptors can apply inhibitory regulation of DA cells (Koga and Momiyama, 2000).

It has been speculated that individual differences in DA functioning may also underlie the personality trait of novelty seeking in humans (Dellu et al., 1996). However, there are substantial species differences in the DA system of rodents and humans (Berger et al., 1991; Frankle et al., 2006). Moreover, it is unclear whether animal models that assess responses to inescapable novelty are homologous to self-reported novelty seeking in humans. 

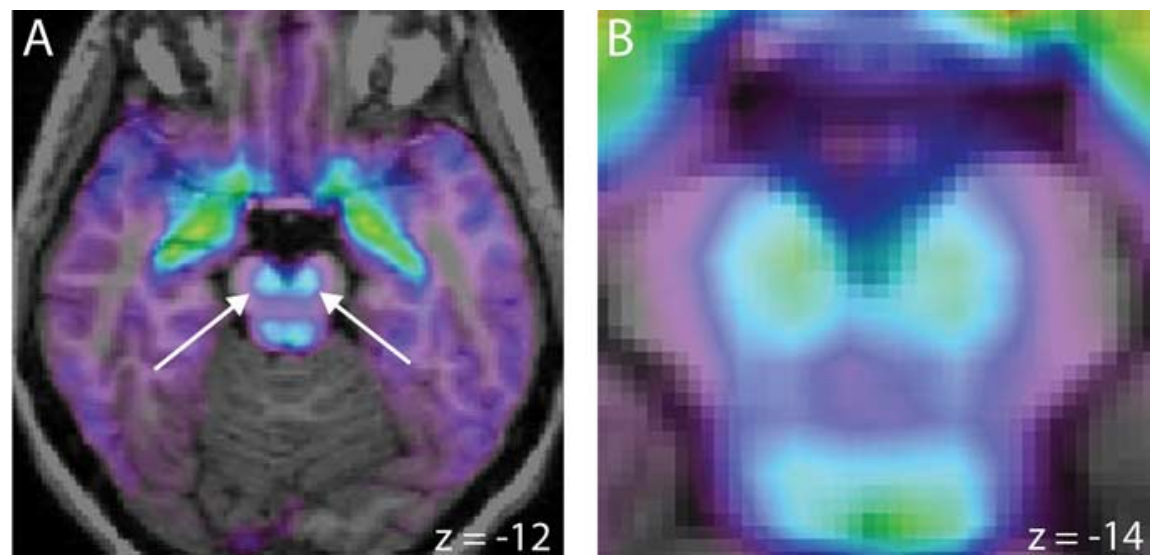

Figure 1. $\left[{ }^{18} \mathrm{~F}\right]$ Fallypride $\mathrm{BP}_{\mathrm{ND}}$ in the DA midbrain of an individual subject. $\boldsymbol{A}$, The two peaks (marked by arrows) correspond to the $S N$. Higher $B P_{N D}$ levels can also be seen in the medial temporal lobe, and the basal forebrain. $\boldsymbol{B}, A$ blowup of the DA midbrain region in the same subject. Significant $\mathrm{BP}_{\mathrm{ND}}$ levels can also be seen in the colliculus at the bottom of the figure. The color scale moves from purple (low: $\mathrm{BP}_{\mathrm{ND}} \geq 0.50$ ), to yellow (high: $\mathrm{BP}_{\mathrm{ND}}>4.0$ ).

To determine the translational ability of animal models to inform the neuropharmacological substrates of human personality, we tested whether individual differences in self-reported novelty seeking are related to $\mathrm{D}_{2}$-like binding potential $\left(\mathrm{BP}_{\mathrm{ND}}\right.$; an index of nondisplaceable receptor availability) in the midbrain of healthy humans. Given that $\mathrm{D}_{2}$-like $\mathrm{BP}_{\mathrm{ND}}$ in the midbrain heavily reflects autoreceptor control of DA neurons, we speculated that novelty-seeking traits would be inversely related to $\mathrm{D}_{2}$-like $\mathrm{BP}_{\mathrm{ND}}$ in the midbrain.

\section{Materials and Methods}

Participants. Thirty-four neurologically and psychiatrically healthy righthanded adult participants (mean age $=23.4$, range 18-38; 18 men, 16 women) completed the study. All participants provided written informed consent approved by the Vanderbilt University Institutional Review Board. Before admission in the PET phase of the study all participants were given a physical exam to assess for contraindications for study participation. Subjects completed a psychiatric interview (Structured Clinical Interview for DSM-IV) (First et al., 1997) to rule out Axis I psychiatric history. Participants were also excluded if they had taken psychostimulants on more than two occasions. Participants were also excluded if they met criteria for nicotine dependence, or were daily cigarette smokers.

Novelty-Seeking Scale. All participants completed the Novelty-Seeking Scale from the Tridimensional Personality Questionnaire (Cloninger, 1987a). Cloninger developed the Novelty-Seeking Scale to assess a hypothesized "heritable tendency toward intense exhilaration or excitement in response to novel stimuli or cues for potential rewards or potential relief of punishment, which leads to frequent exploratory activity in pursuit of potential rewards as well as active avoidance of monotony and potential punishment" (Cloninger, 1987b). The scale contains 34 truefalse questions, distributed across four subscales: NS1: exploratory excitability (vs stoic rigidity), which taps the preference for and response to novelty; NS2: impulsiveness (vs reflection), which taps the speed of decision making; NS3: extravagance (vs reserve), which taps the persons readiness to freely spend money; and NS4: disorderliness (vs regimentation), which taps the extent to which the person is spontaneous and unconstrained by rules and regulations. The questionnaire is scored so that higher scores reflect greater novelty seeking.

Magnetic resonance imaging scanning. Magnetic resonance imaging (MRI) scans of the brain were performed using thin section inversion prepared T1-weighted spoiled gradient recalled sequences [IR SPGR, echo time $(\mathrm{TE})=3.6$, repetition time $(\mathrm{TR})=19, \mathrm{TI}=400,24 \mathrm{~cm}$ field of view] in the sagittal (slice thickness $1.2 \mathrm{~mm}$ ) and coronal (slice thickness $1.4 \mathrm{~mm}$ ) planes. In addition, fast spin echo axial spin density weighted $(\mathrm{TE}=19, \mathrm{TR}=5000,3 \mathrm{~mm}$ thick $)$ and $\mathrm{T} 2$-weighted $(\mathrm{TE}=106, \mathrm{TR}=$
5000, $3 \mathrm{~mm}$ thick) slices were obtained to ensure that participants did not have any structural abnormalities.

Positron emission tomography scanning. $\mathrm{D}_{2}$ like receptor availability was measured with positron emission tomography (PET) and the high affinity $\mathrm{D}_{2} / \mathrm{D}_{3}$ radioligand $\left[{ }^{18} \mathrm{~F}\right]$ fallypride. PET imaging was completed on a GE Discovery LS PET scanner (General Electric). Subjects were positioned in the scanner to allow axial slice collection parallel to the orbitomedial plane with both the superior edge of the cingulate and the inferior temporal cortices within the field of view. $\left[{ }^{18} \mathrm{~F}\right]$ Fallypride $(5 \mathrm{mCi}$, specific activity $>2000 \mathrm{Ci} / \mathrm{mmol}$ ) was then injected over a $30 \mathrm{~s}$ period through an indwelling catheter. Serial scans of increasing duration were performed during the first hour following radiotracer injection. After a $15-20$ min break, a second set of scans was collected over the next $50 \mathrm{~min}$. A second 20-30 min break was given, followed by a third set of scans lasting $50 \mathrm{~min}$. The extended scanning time allowed for stable kinetic model fits in both extrastriatal and striatal brain regions. A measured attenuation correction was performed using rotating rods of ${ }^{68} \mathrm{G} /$ ${ }^{68} \mathrm{Ga}$ before each set of scans.

The GE Discovery LS scanner used in this study has an axial resolution of $4 \mathrm{~mm}$ and in plane resolution of $4.5-5.5 \mathrm{~mm}$ full-width halfmaximum (FWHM) at the center of the field of view. This resolution allows visualization of $\left[{ }^{18} \mathrm{~F}\right]$ fallypride $\mathrm{BP}_{\mathrm{ND}}$ in the substantia nigra (SN)/ ventral tegmental area (VTA) [see Kessler et al. (1984), for a discussion of the spatial resolution requirements for detecting activity in the SN]. Figure 1 displays an example of midbrain $\mathrm{D}_{2}$-like binding in a single participant. In all participants, $\left[{ }^{18} \mathrm{~F}\right]$ fallypride $\mathrm{BP}_{\mathrm{ND}}$ peaks can be seen in the SN. However, the FWHM does not provide an ability to clearly distinguish between different DA cell populations, preventing a clear parcellation of the VTA from the neighboring SN, which possesses higher levels of $\mathrm{D}_{2}$-like receptors. Previous studies have demonstrated good intersubject and intratest-retest reliability for measurement of $\left[{ }^{18} \mathrm{~F}\right]$ fallypride $\mathrm{BP}_{\mathrm{ND}}$ for the DA midbrain at this scanner resolution (Mukherjee et al., 2002; Riccardi et al., 2006). $\left[{ }^{18} \mathrm{~F}\right]$ fallypride binds with high affinity to both presynaptic and postsynaptic $\mathrm{D}_{2}$-like receptors (Mukherjee et al., 1999). However, because DA receptor expression in the midbrain is dominated by the $\mathrm{D}_{2}$-short receptor subtype (Khan et al., 1998), variance in $\left[{ }^{18} \mathrm{~F}\right]$ fallypride $\mathrm{BP}$ within the midbrain is presumed to be driven by individual differences in the $\mathrm{D}_{2}$-short autoreceptors.

Data analysis. To minimize potential modeling errors due to head motion, serial PET scans were coregistered using a mutual information based rigid body algorithm (Wells et al., 1996; Maes et al., 1997). Parametric images of $\mathrm{BP}_{\mathrm{ND}}$ were calculated using the full reference region method (Lammertsma et al., 1996) with the cerebellum serving as the reference region. Although the cerebellum has low levels of $\mathrm{D}_{2}$ receptors (Hurley et al., 2003), they have minimal impact on estimates of $\left[{ }^{18} \mathrm{~F}\right] \mathrm{fal}-$ lypride $\mathrm{BP}_{\mathrm{ND}}$ (Kessler et al., 2000). More importantly, the correspondence between $\mathrm{BP}_{\mathrm{ND}}$ estimates derived from cerebellar reference region and Logan plots (using a metabolite corrected plasma input function) indicate an extremely high correlation $(r>0.99)$ in multiple brain regions (Kessler et al., 2000), indicating that the use of the cerebellar reference region does not introduce any significant error in the relative $\mathrm{BP}_{\mathrm{ND}}$ levels of different brain regions.

Each participant's $\mathrm{BP}_{\mathrm{ND}}$ image was aligned with their $\mathrm{T} 1$-weighted MRI based on the coregistration of the weighted average of the PET dynamic scans to the MRI using a mutual information based rigid body algorithm (Wells et al., 1996; Maes et al., 1997), Each subject's structural $\mathrm{MRI}$ and $\mathrm{BP}_{\mathrm{ND}}$ image was warped into a common stereotactic space based on a nonrigid body coregistration of a composite PET/MRI image to a template PET/MRI (Rohde et al., 2003). To determine the success of the coregistration in the midbrain, we manually labeled several landmarks around the midbrain, including the posterior edge of the right and 
left inferior colliculus, the anterior-most point of the right and left cerebral peduncle and the interpeduncular fossa at $z=-10$, and the inferiormost point of the supramammillary commissure. Of the 34 subjects, 33 showed excellent midbrain coregistration, with no tag varying by $>2 \mathrm{~mm}$ in any direction from the mean coordinate of the tag (across these 33 subjects, the mean distance in any direction from the average tag was $<1$ $\mathrm{mm}$ for every tag examined). Given the spatial resolution of the PET images, this degree of misregistration is at the subvoxel level, and will have negligible impact on the results. The final participant showed greater evidence of misregistration, particularly in terms of the colliculus tags. We attempted to correct this using the FSL-FLIRT program (Jenkinson et al. 2002) with weighting placed on a midbrain mask, but the realigned image still showed evidence of misregistration. Given that a linear registration specific to the brainstem could not correct the alignment issues, we excluded this subject from the final analysis. All primary analyses are therefore reported based on 33 participants, although all reported results remained statistically significant when this participant was included.

Both simple (Pearson product moment) and partial correlations were calculated independently for each voxel of the spatially normalized $\mathrm{BP}$ ND images using custom software that implemented the analyses according to the formulas provided by $\mathrm{Zar}$ (1999). Because the $\mathrm{BP}_{\mathrm{ND}}$ images are inherently smooth relative to the size of the structure of interest, no additional spatial filtering was performed before analysis. Cluster sizes were calculated as all contiguous voxels exceeding a magnitude threshold of $p<0.05$ (uncorrected). For the DA midbrain region, we required an extent threshold of 15 voxels. This extent threshold was based on the measured FWHM maximum (from residuals of $\mathrm{BP}_{\mathrm{ND}}$ images) within the DA midbrain region, and a search region of $\sim 30 \times 18 \times 14 \mathrm{~mm}$ (the search area followed the contours of the midbrain). The extent threshold of 15 voxels achieves a cluster size significance threshold of $p<0.05$ as calculated by Monte Carlo simulation (1000 iterations) using AlphaSim (http://afni.nimh.nih.gov/pub/dist/doc/manual/AlphaSim.pdf). For exploratory analysis of the remainder of the brain, an extent threshold of 72 voxels was required for significance, based on AlphaSim calculations with $p=0.05$, the mean FWHM throughout the brain and inclusion of all voxels with a mean $\mathrm{BP}_{\mathrm{ND}} \geq 0.40$. Studies examining voxelwise correlations between personality traits and neuroimaging data must perform a correction to deal with the problem of multiple comparisons. As described above, for our primary analyses we have emphasized spatial extent criterion to limit the risk of false positive results. This approach allows leniency in terms of effect size (consistent with the typically modest to moderate size of correlations between personality scales and other measures), but limits the ability to detect small volume associations. An alternative approach to correcting for multiple comparisons is to adjust the $p$ value associated with the magnitude of the effect. To obtain corrected $p$ values, we converted $r$-values to Z-scores, and determined significance levels using the ptoz script in FSL (Smith et al. 2004) after determining that the midbrain search region had 23 resolution elements. Except where specifically noted, uncorrected $p$ values are reported.

\section{Results}

Voxelwise correlation analysis revealed a significant inverse association between Total Novelty-Seeking Scores and $\left[{ }^{18} \mathrm{~F}\right]$ fallypride $\mathrm{BP}_{\mathrm{ND}}$ in the $\mathrm{DA}$ midbrain bilaterally (total extent $=89$ voxels, average correlation for entire cluster, $r=-0.44, p<0.01$ ). The peak correlational focus localized to the right SN/VTA region at Talairach coordinates $x=4.5, y=-22, z=-14.5, r=-0.68$, $p<0.00005$ (Fig. 2), with a smaller peak occurring in the left SN $(x=-13, y=-25, z=-11 r=-0.53, p<0.005)$. Because both DA receptor levels and novelty-seeking traits decline with age, we performed a partial correlation analysis controlling for age. Controlling for age had minimal effect on the results (total extent $=$ 71 voxels, average correlation for entire cluster, $r=-0.43, p<$ 0.05). The peak correlations emerged at identical coordinates, and remained highly significant (right, $r=-0.64, p=0.0001$, left $r=-0.51, p<0.005)$. If a more stringent criteria for effect size magnitude is applied, with $p$ values corrected for number of resolution elements in the search region, the peak right SN/VTA focus remains significant in both the original analysis $\left(p_{\text {(corrected) }}<0.005\right)$ and the age-corrected data $\left(p_{\text {(corrected) }}<\right.$ $0.01)$, while the left SN/VTA shows a statistically significant trend.

We additionally analyzed whether gender influenced the association between DA midbrain $\mathrm{BP}_{\mathrm{ND}}$ and novelty seeking (as assessed by the interaction between gender and midbrain $\mathrm{BP}_{\mathrm{ND}}$ in predicting novelty score). These analyses indicated that there was no influence of gender on the relation between novelty seeking and midbrain $\mathrm{BP}_{\mathrm{ND}}$. The pattern of correlations that emerged from analysis of the Total Novelty-Seeking Scale was quite specific and did not reflect a global pattern of lowered levels of $\mathrm{D}_{2}$ like receptors throughout the brain. No other areas of the brain showed correlations of the magnitude or extent of the midbrain. Indeed, only three other areas of the brain reached the a priori 15 voxel threshold after correction for age (an inverse partial correlation in the right thalamus, centered at $x=22, y=-25 z=12$, peak $r=-0.51, p<0.005$, a positive association in the right parahippocampal gyrus, $x=33, y=-18, z=-26$, peak $r=$ $0.54, p<0.005$, and a positive association in the anterior cingulate bilaterally, peak $x=-4, y=7, z=28.5 r=0.48, p<0.05$ ), but none survived a whole brain correction for extent.

To determine whether the individual Novelty-Seeking subscales were related to $\left[{ }^{18} \mathrm{~F}\right]$ fallypride $\mathrm{BP}_{\mathrm{ND}}$ in the midbrain, we performed post hoc voxelwise correlational analyses with each subscale. All 4 subscales of the Novelty-Seeking Scale showed at least moderate negative correlations with the DA midbrain region, but none exceeded the magnitude or extent produced by analysis of total Novelty-Seeking Score. At least 15 voxels showing significance at $p<0.05$ were present for each subscale (additional exploratory analyses of the Novelty-Seeking subscales are described in online supplemental materials, available at www.jneurosci.org).

\section{Discussion}

The present data indicate that novelty-seeking personality traits in humans are associated with reduced $\mathrm{D}_{2}$-like receptor availability in the SN/VTA. Because midbrain $\mathrm{D}_{2}$-like receptors are dominated by somatodendritic autoreceptors, these results suggest a specific inverse relationship between novelty-seeking traits and autoreceptor availability. This observation converges with findings of reduced autoinhibition in high novelty responsive rodents (Marinelli and White, 2000).

Because the DA autoreceptor is a potent regulator of the ability of DA cells to fire (Aghajanian and Bunney, 1977; Lacey et al., 1987; Mercuri et al., 1992, 1997; Adell and Artigas, 2004) individual differences in this autoinhibitory control mechanism would be expected to lead to substantial differences in the impulse properties of DA neurons, and hence DA release. Indeed, in rodents there is an inverse correlation between DA cell firing rates and the extent to which this activity can be suppressed by local application of DA (White and Wang, 1984; Marinelli and White, 2000). High novelty responsive rodents show substantially more frequent and longer-lasting DA bursting activity than low responsive rodents (Marinelli and White, 2000), which may in turn explain the greater levels of basal striatal DA release observed in high novelty responsive rodents (Bradberry et al., 1991; Piazza et al., 1991a; Hooks et al., 1992; Rougé-Pont et al., 1993, 1998) (Fig. 3 ). In addition to providing acute negative feedback on stimulated firing, recent studies of cultured rodent DA neurons suggests that $\mathrm{D}_{2}$-like autoreceptors influence the pacemaker activity 

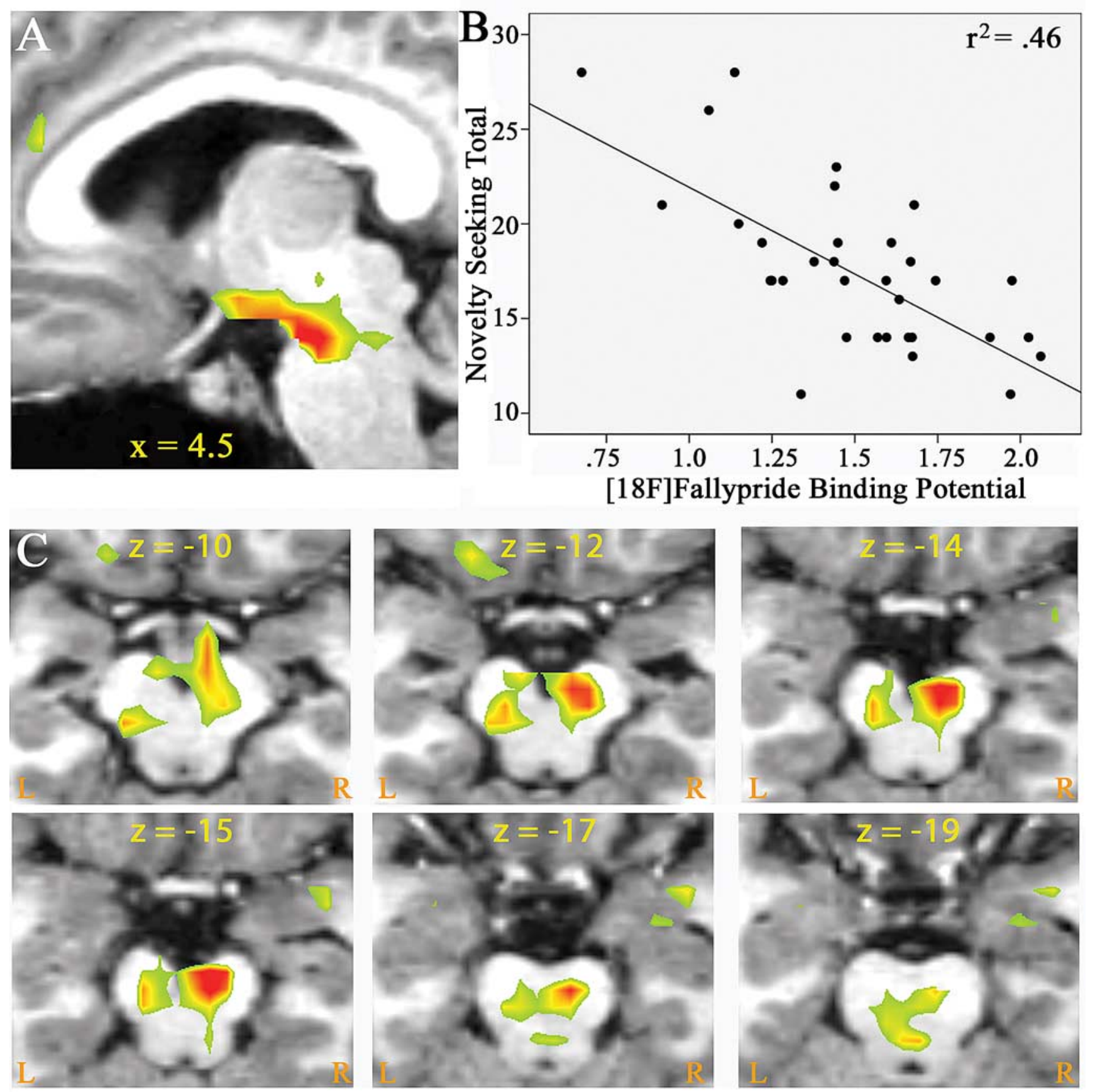

Figure 2. Inverse correlation between $\left[{ }^{18} \mathrm{~F}\right]$ fallypride $\mathrm{BP}_{\mathrm{ND}}$ in the $\mathrm{DA}$ midbrain and total Novelty-Seeking Score. $\boldsymbol{A}$ shows a sagittal slice through the right $\mathrm{SN}$. $\boldsymbol{B}$ provides a scatter plot of each participant's Total Novelty Score and $\left[{ }^{18} \mathrm{~F}\right]$ fallypride $B P_{\mathrm{ND}}$ at the peak coordinate. C displays a series of axial slices through the midbrain ranging from a $z$ of -10 to -19 . In $\boldsymbol{A}$ and $C$, the parametric maps were thresholded to only show voxels with correlations that exceed the $p<0.05$ level (uncorrected) for magnitude, with areas in red exceeding $r=-0.50$. R, Right; L, left.

of DA cells over longer time courses, such that individuals with lower autoreceptor control may have a greater ratio of burst firing to tonic activity (Hahn et al., 2006).

The specific role of DA autoreceptor regulation in influencing novelty-seeking behavior likely reflects the privileged ability of novel stimuli to trigger SN/VTA firing (Ljungberg et al., 1992). Three recent functional MRI studies observed blood oxygen level-dependent (BOLD) responses in the SN/VTA region when healthy humans anticipated or viewed novel pictures or associations (Schott et al., 2004; Bunzeck and Düzel, 2006; Wittmann et al., 2007). Presumably this reflects a burst of DA cell firing in response to novelty. Kakade and Dayan (2002) suggest that this type of novelty-induced phasic firing of DA neurons provides a motivating "exploration bonus" that encourages exploration of stimuli or environments. Based on our current data, individuals with lower autoreceptor levels would be predicted to have a greater "exploration bonus" than those with higher autoreceptor levels.

Increasing data in both human and nonhuman primates indicate that midbrain DA neurons fire in response to predictive reward cues and unpredicted, or underpredicted, rewards (Schultz and Dickinson, 2000; O'Doherty et al., 2002; Bayer and Glimcher, 2005; D'Ardenne et al., 2008; Murray et al., 2008). As a major target of VTA projections, the ventral striatum similarly 
shows increased activity in conjunction with reward cues and positive prediction errors (Berns et al., 2001; O'Doherty et al., 2002; Pagnoni et al., 2002; Knutson and Adcock, 2005; Abler et al., 2006; Yacubian et al., 2006). Indeed, the magnitude of striatal BOLD responses linked to prediction errors is modulated by statewise manipulations of DA (Pessiglione et al., 2006). Given the present data on novelty seeking and DA autoregulation, it follows that high novelty seekers will have enhanced striatal responses during conditions that release DA. Consistent with this hypothesis, Abler et al. (2006) recently demonstrated that individuals scoring high on the exploratory excitability subscale (NS1) show greater ventral striatal BOLD responses than low scorers when exposed to positive prediction errors. Thus, differences in autoregulation may lead not only to differential responses to novelty, but to a broad array of motivational and learning processes that depend on DA.

The correlation between noveltyseeking personality traits and autoreceptor functioning may also contribute to the increased addiction vulnerability of high novelty seekers. In rodents, high novelty responders show increased DA release in response to psychostimulants (Hooks et al., 1991, 1992). While the relationship between DA midbrain $\mathrm{BP}_{\mathrm{ND}}$ for $\left[{ }^{18} \mathrm{~F}\right]$ fallypride and responsiveness to psychostimulants in humans is currently unknown, several studies have reported a relationship between novelty seeking and responses to amphetamine, with high novelty seekers showing enhanced subjective and psychophysiological response to D-amphetamine (Sax and Strakowski, 1998; Hutchison et al., 1999). Similarly, Leyton et al. (2002) reported a correlation between Novelty Seeking and the amount of amphetamine-induced DA release (measured by $\left[{ }^{11} \mathrm{C}\right]$ raclopride displacement) in the ventral striatum in a small sample of healthy human subjects. Boileau et al. (2006) further indicate that novelty seeking predicts the degree to which sensitization develops with repeated doses of amphetamine. Both of these findings may be a direct consequence of the lowered autoreceptor control associated with novelty seeking.

The present data leave open the question of why there is lower midbrain $\mathrm{D}_{2}$-like receptor availability in high novelty-seeking individuals. The answer to this question has a direct bearing on our interpretation of the functional consequences of lowered $\mathrm{D}_{2}$-like $\mathrm{BP}_{\mathrm{ND}}$. One possibility is that there is a lowered ratio of autoreceptors to DA neurons, such that there is less autoreceptor control for each DA neuron. This would be directly consistent with the animal models. However, there are two other possible explanations that would be inconsistent with the animal data, but nevertheless warrant consideration. First, lowered autoreceptor availability could arise if the ratio of autoreceptors to DA neurons is normal, but high novelty seekers have fewer DA neurons. This would lead to an overall lowering of DA functioning, rather than reduced autoreceptor control. However, this is inconsistent with data indicating that Parkinson's patients (who suffer from reductions in DA neurons) have lowered novelty-seeking personality traits (Menza et al., 1993; Fujii et al., 2000). Furthermore, a hy-
High Novelty Seeker - Low Autoreceptor Control

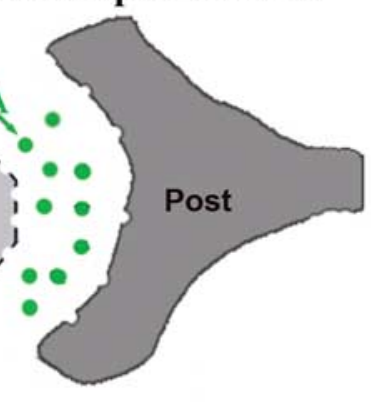

Release Site

Low Novelty Seeker - High Autoreceptor Control

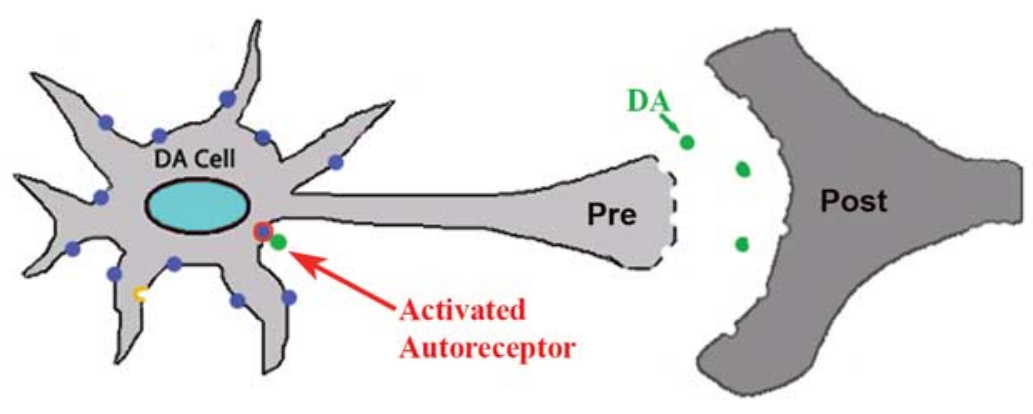

Somatodendritic
Autoreceptors ritic

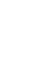

\section{.}

Figure 3. Model of autoreceptor control and individual differences in novelty seeking. Because of their lower number of available somatodendritic autoreceptors, local somatodendritic release of DA in the SN/VTA produces less autoinhibition of DA cell firing in high novelty seekers relative to low novelty seekers. As a consequence, high novelty seekers release more DA in axon target regions when stimulated by novelty or other conditions that cause midbrain DA cells to fire.

pothesis of lowered DA neuron density is inconsistent with the rodent literature indicating that high novelty responders have elevated levels of extracellular DA in the striatum (Bradberry et al., 1991; Piazza et al., 1991a; Hooks et al., 1992). A second possibility is that the lowered autoreceptor availability in high novelty seekers results from individual differences in endogenous DA levels. $\left[{ }^{18} \mathrm{~F}\right]$ Fallypride BP in the midbrain is influenced by endogenous DA levels, such that increases in extracellular DA levels lead to lower $\left[{ }^{18} \mathrm{~F}\right]$ fallypride $\mathrm{BP}_{\mathrm{ND}}$, and decreases in extracellular DA levels increase $\left[{ }^{18} \mathrm{~F}\right]$ fallypride $\mathrm{BP}_{\mathrm{ND}}$ (Riccardi et al., 2006, 2008). Could the high novelty seekers have lowered autoreceptor availability because they have heightened endogenous extracellular DA levels in the midbrain, leading to greater occupation of their autoreceptors? Although possible, this seems unlikely as a singular explanation. Variability in the $\mathrm{SN}^{\prime} \mathrm{s} \mathrm{BP}_{\mathrm{ND}}$ across subjects is larger than the amount of change in $\mathrm{BP}_{\mathrm{ND}}$ induced by pharmacologic manipulations that substantially alter extrasynaptic DA levels (Riccardi et al., 2006, 2008). Moreover, despite their sensitivity to endogenous DA levels, the majority of the variance in $\mathrm{BP}_{\mathrm{ND}}$ levels across individuals remains constant during these pharmacologic manipulations. For instance, reanalysis of the region of interest data from the study by Riccardi et al. (2008), in which endogenous DA levels were lowered with $\alpha$-methyl-paratyrosine, indicates that $>75 \%$ of the variance in $\mathrm{SN} \mathrm{BP}_{\mathrm{ND}}$ in the depleted state was explained by the $\mathrm{BP}_{\mathrm{ND}}$ in the undepleted state. This means that at least in psychiatrically healthy participants, relative levels of available midbrain autoreceptors remain reasonably constant even in the face of pharmacologic manipulations that alter extrasynaptic DA levels. Thus, it seems unlikely that the large variability in $\left[{ }^{18} \mathrm{~F}\right]$ fallypride $\mathrm{BP}_{\mathrm{ND}}$ across subjects could be explained solely based on tonic extracellular levels of DA.

Two additional methodological issues warrant attention in 
considering the present results. First, PET studies in humans are limited by spatial resolution, which makes it difficult to specify the extent of VTA versus SN involvement. The focus of the animal literature has naturally been on the VTA given its projections to the ventral striatum. However, individual differences in autoregulatory factors may impact both the VTA and SN (see discussion in supplemental online materials, available at www. jneurosci.org). Thus, even with higher spatial resolution it is not clear whether the correlated region would be restricted to the VTA. Second, the extent to which the results reflect $D_{2}, D_{3}$, or both receptor subtypes is unknown. Although $\mathrm{D}_{3}$ receptors are less prevalent than $D_{2}$ receptors, a recent study found reduced $D_{3}$ receptor functioning in the midbrain of high novelty responsive rodents (Pritchard et al., 2006). Unfortunately, more specific radioligands would be needed to distinguish the relative contributions of $\mathrm{D}_{2}$ and $\mathrm{D}_{3}$ receptors to novelty seeking in humans.

In summary, the present data show a striking convergence between rodents and humans in the relationship between midbrain autoregulatory factors and novelty related temperamental traits. This convergence emerged despite the fact that we assessed novelty seeking through a self-report measure that taps preferences for novelty, whereas the rodent studies typically measure responses to inescapable novel environments. This is a critical difference in that responses to inescapable novelty are not highly correlated with actual preferences for novelty in rodents (Klebaur et al., 2001; Cain et al., 2004; Zhu et al., 2007) and may relate to a corticosterone-mediated stress response (Piazza et al., 1991b; Rougé-Pont et al., 1998). We speculate that DA autoregulatory factors influence multiple aspects of how organisms respond to novelty and reward, and that individual differences in these factors are manifest in overlapping, albeit nonidentical, temperamental traits across species.

\section{References}

Abler B, Walter H, Erk S, Kammerer H, Spitzer M (2006) Prediction error as a linear function of reward probability is coded in human nucleus accumbens. Neuroimage 31:790-795.

Adell A, Artigas F (2004) The somatodendritic release of dopamine in the ventral tegmental area and its regulation by afferent transmitter systems. Neurosci Biobehav Rev 28:415-431.

Aghajanian GK, Bunney BS (1977) Dopamine "autoreceptors": pharmacological characterization by microiontophoretic single cell recording studies. Naunyn Schmiedebergs Arch Pharmacol 297:1-7.

Bayer HM, Glimcher PW (2005) Midbrain dopamine neurons encode a quantitative reward prediction error signal. Neuron 47:129-141.

Berger B, Gaspar P, Verney C (1991) Dopaminergic innervation of the cerebral cortex: unexpected differences between rodents and primates. Trends Neurosci 14:21-27.

Berns GS, McClure SM, Pagnoni G, Montague PR (2001) Predictability modulates human brain response to reward. J Neurosci 21:2793-2798.

Boileau I, Dagher A, Leyton M, Gunn RN, Baker GB, Diksic M, Benkelfat C (2006) Modeling sensitization to stimulants in humans: an [11C]raclopride/positron emission tomography study in healthy men. Arch Gen Psychiatry 63:1386-1395.

Bradberry CW, Gruen RJ, Berridge CW, Roth RH (1991) Individual differences in behavioral measures: correlations with nucleus-accumbens dopamine measured by microdialysis. Pharmacol Biochem Behav 39:877-882.

Bunzeck N, Düzel E (2006) Absolute coding of stimulus novelty in the human substantia nigra/VTA. Neuron 51:369-379.

Cain ME, Smith CM, Bardo MT (2004) The effect of novelty on amphetamine self-administration in rats classified as high and low responders. Psychopharmacology 176:129-138.

Chen NN, Pan WH (2000) Regulatory effects of D2 receptors in the ventral tegmental area on the mesocorticolimbic dopaminergic pathway. J Neurochem 74:2576-2582.

Cloninger CR (1986) A unified biosocial theory of personality and its role in the development of anxiety states. Psychiatr Dev 4:167-226.
Cloninger CR (1987a) The tridimensional personality questionnaire. Version IV. St. Louis, MO: Department of Psychiatry, Washington University School of Medicine.

Cloninger CR (1987b) A systematic method for clinical description and classification of personality variants. A proposal. Arch Gen Psychiatry 44:573-588.

Cragg SJ, Greenfield SA (1997) Differential autoreceptor control of somatodendritic and axon terminal dopamine release in substantia nigra, ventral tegmental area, and striatum. J Neurosci 17:5738-5746.

D'Ardenne K, McClure SM, Nystrom LE, Cohen JD (2008) BOLD responses reflecting dopaminergic signals in the human ventral tegmental area. Science 319:1264-1267.

Dellu F, Piazza PV, Mayo W, Le Moal M, Simon H (1996) Novelty-seeking in rats-biobehavioral characteristics and possible relationship with the sensation-seeking trait in man. Neuropsychobiology 34:136-145.

Diaz J, Pilon C, Le Foll B, Gros C, Triller A, Schwartz JC, Sokoloff P (2000) Dopamine $\mathrm{D}_{3}$ receptors expressed by all mesencephalic dopamine neurons. J Neurosci 20:8677-8684.

First MB, Spitzer RL, Gibbon M, Williams JB (1997) The structured clinical interview for DMS-IV (SCID-I). Washington, DC: American Psychiatric.

Frankle WG, Laruelle M, Haber SN (2006) Prefrontal cortical projections to the midbrain in primates: evidence for a sparse connection. Neuropsychopharmacology 31:1627-1636.

Fujii C, Harada S, Ohkoshi N, Hayashi A, Yoshizawa K (2000) Crosscultural traits for personality of patients with Parkinson's disease in Japan. Am J Med Genet 96:1-3.

Gurevich EV, Joyce JN (1999) Distribution of dopamine D3 receptor expressing neurons in the human forebrain: comparison with D2 receptor expressing neurons. Neuropsychopharmacology 20:60-80.

Hahn J, Kullmann PH, Horn JP, Levitan ES (2006) $\mathrm{D}_{2}$ autoreceptors chronically enhance dopamine neuron pacemaker activity. J Neurosci 26:5240-5247.

Hooks MS, Jones GH, Smith AD, Neill DB, Justice JB Jr (1991) Response to novelty predicts the locomotor and nucleus accumbens dopamine response to cocaine. Synapse 9:121-128.

Hooks MS, Colvin AC, Juncos JL, Justice JB Jr (1992) Individual differences in basal and cocaine-stimulated extracellular dopamine in the nucleus accumbens using quantitative microdialysis. Brain Res 587:306-312.

Howard MO, Kivlahan D, Walker RD (1997) Cloninger's tridimensional theory of personality and psychopathology: applications to substance use disorders. J Stud Alcohol 58:48-66.

Hurley MJ, Mash DC, Jenner P (2003) Markers for dopaminergic neurotransmission in the cerebellum in normal individuals and patients with Parkinson's disease examined by RT-PCR. Eur J Neurosci 18:2668-2672.

Hutchison KE, Wood MD, Swift R (1999) Personality factors moderate subjective and psychophysiological responses to d-amphetamine in humans. Exp Clin Psychopharmacol 7:493-501.

Jenkinson M, Bannister P, Brady M, Smith S (2002) Improved optimization for the robust and accurate linear registration and motion correction of brain images. Neuroimage 17:825-841.

Kakade S, Dayan P (2002) Dopamine: generalization and bonuses. Neural Netw 15:549-559.

Kessler RM, Ellis JR Jr, Eden M (1984) Analysis of emission tomographic scan data: limitations imposed by resolution and background. J Comput Assist Tomogr 8:514-522.

Kessler RM, Mason NS, Jones C, Ansari MS, Manning RG, Price RR (2000) [18F]N-allyl-5-fluorproplepidepreide (Fallypride): radiation dosimetry, quantification of striatal and extrastriatal dopamine receptors in man. Neuroimage 11:s32.

Khan ZU, Mrzljak L, Gutierrez A, de la Calle A, Goldman-Rakic PS (1998) Prominence of the dopamine D2 short isoform in dopaminergic pathways. Proc Natl Acad Sci U S A 95:7731-7736.

Klebaur JE, Bevins RA, Segar TM, Bardo MT (2001) Individual differences in behavioral responses to novelty and amphetamine self-administration in male and female rats. Behav Pharmacol 12:267-275.

Knutson B, Adcock RA (2005) Remembrance of rewards past. Neuron 45:331-332.

Koga E, Momiyama T (2000) Presynaptic dopamine D2-like receptors inhibit excitatory transmission onto rat ventral tegmental dopaminergic neurones. J Physiol 523:163-173.

Lacey MG, Mercuri NB, North RA (1987) Dopamine acts on D2 receptors 
to increase potassium conductance in neurones of the rat substantia nigra zona compacta. J Physiol 392:397-416.

Lammertsma AA, Bench CJ, Hume SP, Osman S, Gunn K, Brooks DJ, Frackowiak RS (1996) Comparison of methods for analysis of clinical [11C]raclopride studies. J Cereb Blood Flow Metab 16:42-52.

Levant B (1997) The D3 dopamine receptor: neurobiology and potential clinical relevance. Pharmacol Rev 49:231-252.

Leyton M, Boileau I, Benkelfat C, Diksic M, Baker HF, Dagher A (2002) Extracellular dopamine, drug wanting, and novelty seeking. A PET/ $[11 \mathrm{C}]$ raclopride study in healthy men. Neuropharmacology 6:1027-1035.

Ljungberg T, Apicella P, Schultz W (1992) Responses of monkey dopamine neurons during learning of behavioral reactions. J Neurophysiol 67:145-163.

Maes F, Collignon A, Vandermeulen D, Marchal G, Suetens P (1997) Multimodality image registration by maximization of mutual information. IEEE Trans Med Imaging 16:187-198.

Maidment NT, Marsden CA (1985) In vivo voltammetric and behavioural evidence for somatodendritic autoreceptor control of mesolimbic dopamine neurones. Brain Res 338:317-325.

Marinelli M, White FJ (2000) Enhanced vulnerability to cocaine selfadministration is associated with elevated impulse activity of midbrain dopamine neurons. J Neurosci 20:8876-8885.

Menza MA, Golbe LI, Cody RA, Forman NE (1993) Dopamine-related personality traits in Parkinson's disease. Neurology 43:505-508.

Mercuri NB, Calabresi P, Bernardi G (1992) The electrophysiological actions of dopamine and dopaminergic drugs on neurons of the substantia nigra pars compacta and ventral tegmental area. Life Sci 51:711-718.

Mercuri NB, Saiardi A, Bonci A, Picetti R, Calabresi P, Bernardi G, Borrelli E (1997) Loss of autoreceptor function in dopaminergic neurons from dopamine D2 receptor deficient mice. Neurosci 79:323-327.

Millan MJ, Gobert A, Newman-Tancredi A, Lejeune F, Cussac D, Rivet JM, Audinot V, Dubuffet T, Lavielle G (2000) S33084, a novel, potent, selective, and competitive antagonist at dopamine $\mathrm{D}(3)$-receptors: I. Receptorial, electrophysiological and neurochemical profile compared with GR218,231 and L741,626. J Pharmacol Exp Ther 293:1048-1062.

Mukherjee J, Yang ZY, Brown T, Lew R, Wernick M, Ouyang X, Yasillo N, Chen CT, Mintzer R, Cooper M (1999) Preliminary assessment of extrastriatal dopamine D-2 receptor binding in the rodent and nonhuman primate brains using the high affinity radioligand, 18F-fallypride. Nucl Med Biol 26:519-527.

Mukherjee J, Christian BT, Dunigan KA, Shi B, Narayanan TK, Satter M, Mantil J (2002) Brain imaging of F-18-fallypride in normal volunteers: Blood analysis, distribution, test-retest studies, and preliminary assessment of sensitivity to aging effects on dopamine D-2/D-3 receptors. Synapse 46:170-188.

Murray GK, Corlett PR, Clark L, Pessiglione M, Blackwell AD, Honey G, Jones PB, Bullmore ET, Robbins TW, Fletcher PC (2008) Substantia nigra/ventral tegmental reward prediction error disruption in psychosis. Mol Psychiatry 13:239, 267-276.

O'Doherty JP, Deichmann R, Critchley HD, Dolan RJ (2002) Neural responses during anticipation of a primary taste reward. Neuron 33:815-826.

Pagnoni G, Zink CF, Montague PR, Berns GS (2002) Activity in human ventral striatum locked to errors of reward prediction. Nat Neurosci 5:97-98.

Pessiglione M, Seymour B, Flandin G, Dolan RJ, Frith CD (2006) Dopamine-dependent prediction errors underpin reward-seeking behaviour in humans. Nature 442:1042-1045.

Piazza P, Rougé-Pont F, Deminière JM, Kharoubi M, Le Moal M, Simon H (1991a) Dopamine activity is reduced in the prefrontal cortex and increased in the nucleus acumbens of rats predisposed to develop amphetamine self-administration. Brain Res 567:169-174.

Piazza PV, Deminière JM, Le Moal M, Simon H (1989) Factors that predict individual vulnerability to amphetamine self-administration. Science 245:1511-1513.

Piazza PV, Maccari S, Deminière JM, Le Moal M, Mormède P, Simon H (1991b) Corticosterone levels determine individual vulnerability to amphetamine self-administration. Proc Natl Acad Sci U S A 88:2088-2092.

Pickel VM, Chan J, Nirenberg MJ (2002) Region-specific targeting of dopa- mine D2-receptors and somatodendritic vesicular monoamine transporter 2 (VMAT2) within ventral tegmental area subdivisions. Synapse 45:113-124.

Pritchard LM, Logue AD, Taylor BC, Ahlbrand R, Welge JA, Tang Y, Sharp FR, Richtand NM (2006) Relative expression of D3 dopamine receptor and alternative splice variant D3nf mRNA in high and low responders to novelty. Brain Res Bull 70:296-303.

Riccardi P, Li R, Ansari MS, Zald D, Park S, Dawant B, Anderson S, Doop M, Woodward N, Schoenberg E, Schmidt D, Baldwin R, Kessler R (2006) Amphetamine-induced displacement of [18F] fallypride in striatum and extrastriatal regions in humans. Neuropsychopharmacology 31:1016-1026.

Riccardi P, Baldwin R, Salomon R, Anderson S, Ansari MS, Li R, Dawant B, Bauernfeind A, Schmidt D, Kessler R (2008) Estimation of baseline dopamine D2 receptor occupancy in striatum and extrastriatal regions in humans with positron emission tomography with [18F] fallypride. Biol Psychiatry 63:241-244.

Rohde GK, Aldroubi A, Dawant BM (2003) The adaptive bases algorithm for intensity based non-rigid image registration. IEEE Trans Med Imaging 22:1470-1479.

Rougé-Pont F, Piazza PV, Kharouby M, Le Moal M, Simon H (1993) Higher and longer stress-induced increase in dopamine concentrations in the nucleus accumbens of animals predisposed to amphetamine selfadministration. A microdialysis study. Brain Res 602:169-174.

Rougé-Pont F, Deroche V, Le Moal M, Piazza PV (1998) Individual differences in stress-induced dopamine release in the nucleus accumbens are influenced by corticosterone. Eur J Neurosci 10:3903-3907.

Sax KW, Strakowski SM (1998) Enhanced behavioral response to repeated $\mathrm{d}$-amphetamine and personality traits in humans. Biol Psychiatry 44:1192-1195.

Schott BH, Sellner DB, Lauer CJ, Habib R, Frey JU, Guderian S, Heinze HJ, Düzel E (2004) Activation of midbrain structures by associative novelty and the formation of explicit memory in humans. Learn Mem 11:383-387.

Schultz W, Dickinson A (2000) Neuronal coding of prediction errors. Annu Rev Neurosci 23:473-500.

Sesack SR, Aoki C, Pickel VM (1994) Ultrastructural-localization of $\mathrm{D}_{2}$ receptor-like immunoreactivity in midbrain dopamine neurons and their striatal targets. J Neurosci 14:88-106.

Smith SM, Jenkinson M, Woolrich MW, Beckmann CF, Behrens TE, Johansen-Berg H, Bannister PR, De Luca M, Drobnjak I, Flitney DE, Niazy RK, Saunders J, Vickers J, Zhang Y, De Stefano N, Brady JM, Matthews PM (2004) Advances in functional and structural MR image analysis and implementation as FSL. Neuroimage 23 [Suppl 1]:S208-S219.

Sokoloff P, Diaz J, Le Foll B, Guillin O, Leriche L, Bezard E, Gross C (2006) The dopamine D3 receptor: a therapeutic target for the treatment of neuropsychiatric disorders. CNS Neurol Disord Drug Targets 5:25-43.

Tepper JM, Sun BC, Martin LP, Creese I (1997) Functional roles of dopamine $D_{2}$ and $D_{3}$ autoreceptors on nigrostriatal neurons analyzed by antisense knockdown in vivo. J Neurosci 17:2519-2530.

Wells WM 3rd, Viola P, Atsumi H, Nakajima S, Kikinis R (1996) Multimodal volume registration by maximization of mutual information. Med Image Anal 1:35-51.

Westerink BH, Kwint HF, deVries JB (1996) The pharmacology of mesolimbic dopamine neurons: a dual-probe microdialysis study in the ventral tegmental area and nucleus accumbens of the rat brain. J Neurosci 16:2605-2611.

White FJ, Wang RY (1984) A10 dopamine neurons: role of autoreceptors in determining firing rate and sensitivity to dopamine agonists. Life Sci 34:1161-1170.

Wittmann BC, Bunzeck N, Dolan RJ, Düzel E (2007) Anticipation of novelty recruits reward system and hippocampus while promoting recollection. Neuroimage 38:194-202.

Yacubian J, Gläscher J, Schroeder K, Sommer T, Braus DF, Büchel C (2006) Dissociable systems for gain- and loss-related value predictions and errors of prediction in the human brain. J Neurosci 26:9530-9537.

Zar JH (1999) Biostatistical analysis. Upper Saddle River, NJ: Prentice Hall.

Zhu J, Bardo MT, Bruntz RC, Stairs DJ, Dwoskin LP (2007) Individual differences in response to novelty predict prefrontal cortex dopamine transporter function and cell surface expression. Eur J Neurosci 26:717-728. 